\title{
El docente-futor competente como acompañante del estudiante del nivel superior en su proyecto de vida
}

Licenciada en Contaduría Pública, con Maestría en Ciencias de la Educación. Estudiante del Doctorado en Ciencias Pedagógicas. Docente
tiempo completo de la Benemérita Universidad Autónoma de Puebla en la Licenciatura en Procesos Educativos. Puebla, México.

Recibido: 1 de julio del 2013

\section{RESUMEN}

Es evidente que los cambios sociales, económicos, políticos yeducativos llevan a replantear el rol del docente, entre sus funciones actualmente destacan la docencia, la investigación, la gestión y la tutoría, entonces aparece la figura del docente-tutor como el acompañante del estudiante del nivel superior a lo largo de su estancia en la universidad. Este docente tutor debe desarrollar competencias que le permitan guiar al estudiante en la construcción de su proyecto de vida para que se inserte de manera exitosa en el campo personal, social y laboral. En el presente trabajo se fundamenta desde la filosofía, la sociología, la psicología, la pedagogía y la didáctica como ciencias de la educación, la relevancia del proceso de desarrollo de las competencias del docente tutor para actuar en la formación integral de los estudiantes asignados en la acción tutorial que contribuya a desarrollar su proyecto de vida.

\section{PALABRAS CLAVE}

Docente-tutor, proyecto de vida, competencias para la acción tutorial.
Aceptado: 1 de febrero del 2014 project responsible to be inserted successfully in the field personal, social and professional. This present work is to substantiate from philosophy, sociology, psychology, pedagogy and didactic the importance of having a competent tutor teacher to act preventively in the formation of the student.

\section{KEY WORDS}

Teacher-tutor, student's life project, competent tutor.

\section{INTRODUCCIÓN}

El encargo social que actualmente se plantea a la educación del nivel superior, es formar alumnos competentes para la vida. Por ello las Instituciones de Educación Superior (IES) requieren replantear sus metas para dar respuesta a estas necesidades, de ahí que es importante que los principales actores del proceso estén preparados para ello. La formación docente por competencias abre 
un abanico de posibilidades desde los diferentes escenarios internacionales y México no es la excepción. Un área que no se ha valorizado en su totalidad y puede ser una respuesta para contribuir a la formación del alumno, es la tutoría, como estrategia transversal al currículum (Romo, 2010, Álvarez, 2002, BUAP; 2006, Sabaté, 2006) que de manera sistematizada e incluyente lo acompañe en la conformación de su proyecto de vida.

De esta manera para Reyes, A. (2009:9) la acción tutorial "se puede ver como un proceso de vinculación sistemático y progresivo de larga duración para un buen desempeño del estudiante en su formación profesional universitaria, con la finalidad de aumentar su capacidad de rendimiento en la carrera que elige y para apoyar la formación integral del estudiante".

La acción tutorial en México se plantea como una necesidad en los diferentes niveles educativos, ANUIES(2002), incluso hace recomendaciones generales sobre la planeación tutorial para que las IES la implementen en sus respectivos espacios adaptándose al contexto específico, también ya se habla de la red nacional de tutoría y desde las políticas gubernamentales; otro referente del trabajo tutorial del docente del nivel superior, es el programa para el mejoramiento del profesorado (PROMEP), cuyo objetivo es contribuir a elevar la calidad de la educación mediante el desarrollo de profesionistas competentes a través de un profesorado de tiempo completo que eleva permanentemente su nivel de habilitación con base en los perfiles adecuados al subsistema de educación superior (Diario Oficial, 2011) y el programa nacional de becas para el nivel superior (PRONABES), pues entre los requisitos de dicho programa se establece el "Asignar un tutor a cada uno de los becarios dentro del grupo de tutores del programa educativo, procurando que éste cuente con el perfil idóneo reconocido por el PROMEP-SESIC de la SEP, para coadyuvar a su buen desempeño académico y terminación oportuna de los estudios"(Diario oficial, 2005). De ahí que las universidades están trabajando, estableciendo diversas estrategias de acción, sin embargo todavía estos proyectos no se han concretado y la formación del docente todavía no se solidifica.

Siendo una necesidad que desde el mismo contexto social se debe atender pues el impacto de la acción tutorial no queda en el aula y el espacio de la universidad, se refleja en la conformación de un individuo preparado para ejercer la ciudadanía de manera responsable. Por ello el encargo social conferido al docente-tutor universitario deberá llevarlo a formarse de manera integral desarrollando las competencias necesarias en las dimensiones: ético- personal, pedagógica-áulica-, formativa, social y de gestión, pues de esta manera tendrá las herramientas para formar a un estudiante integral y apoyarlo en la conformación de su proyecto de vida responsable.

De manera que, potenciar la acción tutorial en las universidades representa un reto, que de acuerdo a A. Romo (20011) se debe reorientar la forma en que interactúan los principales actores en el proceso de enseñanza y sus fines, ya que tradicionalmente la atención está centrada en el docente y no en quien esencialmente recibe la nueva educación: el estudiante. Si bien el papel protagónico es del estudiante, la figura del docente - tutor es un elemento clave siempre y cuando tengamos claridad en cuanto al perfil que éste debe considerar en su quehacer pedagógico que le permita entender la tutoría como una práctica inherente a su rol como docente. Mora subraya que "desde la tutoría, el profesor puede orientar o ayudar al alumno, a partir de su situación y cualificación propia de profesor con una acción que realiza además y en paralelo a su propia acción como docente" (1998, citado en Romo, 2011:31)).

El modelo educativo Minerva de la Benemérita universidad Autónoma de Puebla (BUAP) reconoce la necesidad de la formación docente para atender las demandas actuales de la sociedad. Se sugiere que dicha formación asuma la necesidad de profesionalizar adecuadamente al 
docente-tutor, pues se infiere que deberá generar ambientes de aprendizaje idóneos a las necesidades del contexto; ello implicará, por tanto desempeñar una docencia integral e innovadora, pues la actual función de la tutoría es entendida como inherente a la función docente.

Así pues, la formación del docente-tutor por competencias para la acción tutorial se muestra como una alternativa interesante, digna de tomar en cuenta y fortalecer en este nivel.

\section{DESARROLLO}

Las IES trabajan bajo el supuesto de la atención a la demanda de la matrícula solicitante, que no siempre es aceptada en su totalidad, también intentan atender la necesidad planteada por la sociedad a través del modelo educativo y perfil de egreso. Una vez que los estudiantes ingresan a las universidades comienza la ardua labor por dar respuesta oportuna y formar al individuo, pero entonces se prioriza la instrucción, pues ésta otorgará la calidad requerida a nivel global, avalará la certificación de los programas de calidad, demostrando que estos programas de estudios cumplen con los requisitos y se hace un gran esfuerzo por lograr dicha instrucción, donde el estudiante principalmente desarrolle las competencias disciplinares y laborales, dando por hecho que en este nivel éstas son las demandas y aspiraciones del estudiante para insertarse al mundo laboral y tener éxito. Pero no es así, pues lo demuestran los altos índices de deserción, según la OCDE (2010), en promedio el treinta y ocho por ciento de los estudiantes no concluye sus estudios universitarios y del porcentaje restante sólo un cuarenta y siete por ciento aproximadamente (46.7 \%) se titula en las instituciones públicas (informe del presidente Fox, 2007).

Por otra parte existe la solicitud de sujetos adaptables al cambio, que sean capaces de tolerar las frustraciones, que puedan interrelacionarse con los otros individuos sociales, que acepten la diversidad y la valoren como opor- tunidad más que como obstáculo, que sean responsables de su formación continua y de las consecuencias de sus actuaciones responsables o no. En su vida personal, social y laboral; que sean capaces de enfrentarse al mundo científico, tecnológico, ecológico y globalizado, que estén aptos para aprender a aprender. Así pues todo lo anteriormente planteado lleva a pensar y reflexionar sobre, qué es lo que está pasando en las universidades, realmente se está insertando al mundo laboral, social y familiar a individuos formados para la vida y cómo las universidades aspiran a solucionar estas necesidades.

Además de la instrucción hay que formar al estudiante como un ser humano preparado para la vida; así que la probable respuesta sería la acción tutorial, pero cómo entenderla. En una gran cantidad de literatura, como indica Colunga (2009), es posible localizar diferentes definiciones y comprensiones en torno al término tutoría. La tutoría ha sido entendida de formas disímiles: como servicio educativo, como actividad pedagógica o conjunto de acciones pedagógicas desplegadas con sistematicidad por una persona experta, como un tipo particular de práctica pedagógica, como estrategia pedagógica, como variante de atención educativa, como labor formativa de un personal pedagógico especializado, como sistemas solidarios y organizados de apoyo pedagógico, como procesos de acompañamiento, ayuda y orientación que asumen un carácter esencialmente formativo, como modalidad de docencia, como recurso de apoyo en las instituciones docentes, como orientación educativa, como un tipo especial de interrelación tutor-tutelado. Todas estas acepciones resultan válidas y favorecen la comprensión de la labor que han venido desarrollando los tutores de acuerdo a los reclamos y demandas de la sociedad y de las instituciones universitarias. Para la autora del presente trabajo la acción tutorial debe considerarse como parte inherente a las funciones del profesor, es un área que se puede explorar y explotar como alternativa para la formación integral del alumno mediante un acompañamiento de manera transversal al currículo, de manera sistemática e 
incluyente. Sin embargo actualmente la tutoría tiene un carácter aislado, no significativo para el proceso de formación de la universidad, basado en lo academicista y administrativo, entendido únicamente como seguimiento a la trayectoria académica del estudiante y apoyo en trámites administrativos; siendo que la tutoría requiere de un carácter sociointegral, entendiendo a esto como la inserción del alumnos al contexto universitario y a la vez a la sociedad, mediante un acompañamiento del docente-tutor durante su estancia en la institución, tanto en el ámbito académico, como el social, personal y laboral. En México a diferencia de otros países el papel del tutor es necesario para facilitar la etapa de transición que el estudiante sufre entre los mundos de los que proviene y le son familiares hacia el mundo de la educación superior (Porter, 2010). Así pues todavía existe la necesidad de ahondar en su estudio, sensibilizar a los distintos agentes educativo y trabajar la tutoría de manera adecuada, pues a pesar de que distintos autores y organizaciones como, Menchén, F. (1999), Müller, M. (2001), Comellas, J. (2002), Álvarez, P. (2002), Romo, A. (2005), Colunga, S. (2009), ANUIES (2009), Romo (2011) coinciden en su importancia y trascendencia, la acción tutorial no se ha consolidado en este nivel y el docente no está formado para ejercerla de manera adecuada.

Planteada la necesidad de la formación docente en competencias para el ejercicio de la acción tutorial que contribuya al desarrollo integral del estudiante del nivel superior, analicemos los fundamentos teóricos desde la perspectiva de las Ciencias de la Educación.

El desarrollo de las instituciones educativas se sustenta en los aportes que las diferentes ciencias proporcionan al quehacer educativo, será importante considerar algunas contribuciones que de ellas emanan y permiten fundamentar el carácter científico de la formación docente por competencias para la acción tutorial como apoyo al proyecto de vida de los alumnos del nivel superior. De esta manera las Ciencias de la Educación, al ser ante todo ciencias éticas, interesadas en el estudio científico de los distintos aspectos de la educación en sociedades y culturas determinadas, describen, analizan y explican los fenómenos educativos considerando el perfeccionamiento del ser humano, de la comunidad y de la sociedad, entre ellas se retoman a la filosofía, la sociología, la psicología, la pedagogía y la didáctica que darán soporte a la fundamentación de la presente propuesta.

Desde la filosofía y la sociología existe el supuesto que la realidad concreta en la que tiene lugar la vida social, la crea y determina la conciencia de los individuos. Considerando este proceso como una totalidad dialéctica que se manifiesta a través de todos y cada uno de los procesos y fenómenos singulares que lo integran y le dan sentido. (Marx, citado en Cortes 1977). El proceso de formación integral del estudiante se fundamenta en que el mismo se desarrolle para su actuar en sociedad para acompañar al estudiante en la formación de la conciencia de un individuo complejo, individual, autónomo e integral, capaz de responder a las demandas histórico sociales en su diario acontecer. No se puede llevar a cabo la acción tutorial con enfoque unilateral encaminándola a la formación como profesional de determinada carrera. Esto si bien es importante aleja el objeto de desarrollo de la conciencia y la personalidad del individuo como un individuo autónomo, capaz de tomar decisiones y de trazarse metas que lo conduzcan a lograr los objetivos más profundos de desarrollo como ser humano.

En la actualidad las limitaciones de la acción tutorial se van acumulando en el tránsito del estudiante por los diferentes niveles educacionales y es el nivel superior al que le corresponde buscar la totalidad en el proceso formativo. El nivel superior tiene como responsabilidad la formación de esos individuos conscientes que se insertarán en una sociedad compleja y que en el futuro dirigirán la política, la economía, las empresas, el mercado; desarrollarán proyectos tecnológicos y científicos e incluso orientarán la misma educación del país para la continuidad del desarrollo. 
Por otra parte, desde el punto de vista de la sociología es sabido que las relaciones establecidas entre los individuos de una sociedad serán definitorias del desarrollo de la misma, por lo que la personalidad del individuo es resultado de su historia en un ambiente sociohistórico concreto y sobre bases o premisas biológicas que hacen posible el reflejo humano de la realidad. Se basa en las experiencias en grupos e instituciones, de los vínculos significativos conformando la esencia social que deberá ser asumida por las instituciones universitarias, coincidiendo con Fernando Savater (1997), cuando dice "hay que nacer para humano, pero sólo se llega plenamente a serlo cuando los demás contagian su humanidad a propósito", ello se logra implicando una trama de relaciones necesarias con otros seres humanos, estos agentes socializadores educativos y el vínculo socialización-individualización connota todo proceso pedagógico.

Así mismo el medio social condiciona la formación para interactuar con el contexto, transformarlo y transformarse a sí mismo, por ello se actúa en consecuencia de las necesidades de responder a las demandas sociales (Matos, 2009), ahora se sabe que dicha sociedad demanda alumnos competentes y por tanto un docente también competente que pueda acompañar al alumno durante su estancia en la universidad, como una intervención transversal a su formación, desde el ejercicio de la acción tutorial, pero además como aporta Vigotsky la formación es intencional, consciente y responsable. De ahí la necesidad desde el enfoque sociológico de que la acción tutoral se lleve a cabo de manera consciente y planificada para lo cual es necesario formar el docente tutor en un conjunto de competencias que le permitan ir construyendo el desarrollo de la personalidad de los estudiantes que atiende en búsqueda no de acciones pasajeras en el tránsito por la Universidad sino de un conjunto de actividades que necesariamente conllevan a la elaboración del proyecto de vida de los mismos.

De aquí derivaría la trascendencia de una buena acción tutorial en el acompañar al estudiante en la concientización, la reflexión, la autodirección y la planeación con visión a futuro de su proyecto responsable de vida, donde logre esa autonomía ideológica y laboral de manera responsable, impactando en su desarrollo personal, educativo, laboral y social; por tanto en la mejora de la sociedad, participando como un ciudadano responsable, solidario y honesto.

Así mismo se asume en esta investigación el enfoque socioformativo de las competencias que se inscribe en la educación humanista (Tobón, 2009) y avala que en las instituciones educativas se forme la conciencia sobre los valores, considerando que el humano "es un ser de relación: empieza a existir gracias a otro, dentro de otro e inmerso en la realidad de otro que le acoge" (Delgado, 1995, p.9; citada por Pimienta, 2007, p.4). Ello implica considerar en los diversos espacios educativos la convivencia, la solidaridad, la justicia, el respeto y la búsqueda de la autorrealización (Tobón y Fernández, 2004; Tejeda y Tobón, 2006; Tobón, García Fraile, Rial y Carretero, 2006; Tobón, Montoya, Ospina, González y Domínguez, 2006). A su vez la educación debe promover el pensamiento complejo, para la formación integral y las cosas se asuman en un sistema y totalidad, es decir incluir lo físico, lo espiritual, lo social y lo mental llevando a desarrollar, elaborar y consolidar en los estudiantes su proyecto ético de vida. Por ello la necesidad del enfoque complejo de la formación por competencias del docente tutor debido a la diversidad de conocimientos, habilidades, destrezas, actitudes y valores que debe tener el tutor para encarar las diferentes aristas que desde lo físico, lo espiritual, lo social y lo mental han de caracterizar el proyecto de vida que debe encarar el estudiante en su tránsito por la institución de Educación Superior.

Otro elemento interesante que contribuye a entender el quehacer de la acción tutorial es pensar en el hombre como una concepción organísmica, es decir un ser impulsado desde sí mismo hacia la autorrealización, un ser capaz de orientarse, dirigirse, siempre que se den las 
condiciones (Rogers, 1999, citado en Pimienta, 2007). Tales condiciones son las que se exigen en los momentos actuales, el proceso de desarrollo de las competencias para la acción tutoral que en opinión de esta autora deben concretarse en un conjunto de acciones incluidas en una estrategia para la Facultad de Filosofía y Letras de la BUAP.

La orientación y el acompañamiento que desde la tutoría se brinda deberá llevar a que el estudiante del nivel superior se forme de manera integral con un proyecto ético de vida sólido (Tobón 2010, 2011) que le permita su autobúsqueda, su realización plena, un individuo consciente, socialmente responsable, respetuoso, colaborativo, capaz de desenvolverse en una sociedad que plantea muchas realidades complejas como la desigualdad, la pobreza, la injusticia, la desintegración social, una sociedad materialista y capaz de responder solidariamente al encargo social. Pero para que esto se logre tiene que llevarse un proceso de desarrollo de las competencias que permitan a los docentes tutores cumplir con tales expectativas.

Ahora bien, considerando algunos aspectos psicológicos para que dicho estudiante pueda madurar en la conformación de un individuo social, deberá adjudicarse los productos de la cultura humana en el curso del contacto con sus semejantes, dicha adaptación implica el proceso de modificación de las facultades y características de los individuos por exigencia del medio, esta apropiación es un proceso activo, de interacción con los objetos y los individuos y de reconstrucción personal. El individuo recurre a distintas interpretaciones y resuelve problemas en función de sus características personales idiosincrásicas, sus ideas, conocimientos, experiencia e intereses y dentro de estos productos de la cultura humana aparece la importancia de la actividad y la comunicación Galperin (1982), como teorías complementarias, que se dan en la vida cotidiana del estudiante y van conformando su personalidad e impactan en la dirección de su comportamiento, situación en la que está involucrada la acción tutorial, pues a través de ella se desea conformar este sujeto integral, donde el individuo va madurando y desarrollando su personalidad combinando factores internos y externos de acuerdo al momento histórico en que vive, tomando en cuentas sus características particulares, sus vivencias, creencias, aprendizajes y experiencias a lo largo de su estancia en la universidad mediante una comunicación y actuación asertiva. Será importante que el tutor domine las etapas por donde transcurre el pensamiento como lo plantea la teoría de la formación Galperin (1982), además hay que tomar en cuenta las etapas del desarrollo cognitivo de Piaget (1985) para comprender los momentos por los que transcurren los procesos del individuo y conocer la personalidad del alumno. Un tutor deberá establecer empatía, inspirar confianza, que entienda los procesos de adaptación y la forma de responder ante los retos que se le presentan al alumno, siendo entonces capaz de acompañar al tutorado hacia el logro de metas personales, de su independencia y que sea capaz de tomar decisiones importantes de su proyecto de vida responsable, pues Moreno, G. (1999) plantea que el aprendizaje suele desarrollarse al enfrentar a la persona a una situación nueva a la que debe responder, si la situación está de acuerdo a su realidad le será posible intentar una respuesta, se trata de dar una respuesta adecuada, por lo tanto la persona debe elegir cuidadosamente a qué actividades debe responder.

Una vez realizadas las actividades escogidas: si se logró lo propuesto, la persona quedará dispuesta a iniciar nuevos aprendizajes y si no se logró necesitará elegir otras actividades o repetir las anteriores hasta conseguirlo, esto fortalece la acción tutorial al concientizar al alumno y llevarlo a la auto reflexión y a la acción que es lo que ayudará a formar su carácter y a planear a corto, mediano y largo plazo su trayectoria escolar, su plan de vida personal y social, pues actualmente el individuo no puede verse aislado y sólo compitiendo, sino colaborando con los otros, logrando esa humanidad. 
Por tanto, para que la actividad se lleve a cabo en la mejor forma, es necesaria la comunicación. El ser humano necesita vivir en comunicación para aplicar conocimientos y solucionar problemas de la colectividad que el momento histórico le presente, en la acción tutorial este elemento particularmente resultará fundamental, pues el acompañamiento que el tutor realice con el alumno debe ser en una ambiente de comunicación amplia, en un clima de confianza, asertiva, sistemática y colaborativa.

Se parte entonces del criterio psicológico tener en cuenta que no todas las personas tienen y logran el desarrollo de altos niveles de comunicación con sus semejantes, pero en esta relación del tutor con sus estudiantes se tiene que favorecer por altos niveles de confianza y asertividad que contribuyan a revelar las limitaciones para poder trazar acciones en el desarrollo del proyecto de vida del estudiante y que este no se vea truncado por los factores que como sabemos en la actualidad entorpecen el camino hacia un éxito profesional y social como son los desvíos de la conducta, los problemas de falta de interés por el estudio, problemas de adicción o embarazos no deseados, etc.

Y claro, por la otra parte, la formación del docente en competencias comunicativas, deberá ser congruentemente desarrollada como proceso entre sujetos que participan de manera activa y consiente. El intercambio de información (transmitirse su realidad psicológica, los valores sociales, conocimientos y desarrollar habilidades para la interacción exitosa con otras personas), que se da en la comunicación, es esencial para lograr el carácter activo y participativo que debe adquirir la acción tutorial y esa comunicación del docente tutor lo llevará a interrelacionarse no sólo con el tutorado, sino con los otros tutores, con los directivos, administrativos, con otras instituciones escolares, con organizaciones del sector privado y gubernamental relacionadas con el ámbito laboral, con diferentes grupos sociales, con redes que apoyen esta acción tutorial y con la familia.
En el proceso de formación docente para la acción tutorial se presenta la probable respuesta a la demanda de la sociedad, pues actualmente esta requiere un docente comprometido con la sociedad, un ser humano que lleve al alumno a concientizarse de las problemáticas de su entorno con la finalidad de responder al encargo social, un docente que forme un ser humano responsable para la vida, un docente que comprenda al otro, un docente que sepa escuchar y comunicar de manera asertiva, un docente que sea incluyente pudiendo atender a la diversidad, apoyar en la formación de la personalidad del estudiante, llevándolo a madurar, un docente que sepa gestionar los procesos diversos implicado en su actuación en el ejercicio de su rol de docente-tutor, con una mirada totalizadora desde los diferentes aspectos que contempla este enfoque complejo que es el proyecto de vida que debe tener el estudiante y las competencias que debe desarrollar el tutor para lograr dicho objetivo.

En la acción tutorial, donde se establecen directamente las relaciones docente-tutor-tutorado, se pretende potencializar el proceso de formación del alumno, en consideración con lo que Vigotsky denomina zona de desarrollo próximo, que es la distancia entre lo que el sujeto puede hacer por sí mismo, de forma independiente y lo que sólo puede hacer con la ayuda del otro y que representa sus potencialidades, o sea, aquello que en un futuro cercano ya podrá realizar por sí mismo, este proceso tutorial implicará la guía, el acompañamiento del alumno a lo largo de su proceso mediante la promoción de dichas zonas.

El docente-tutor, facilita la activación de potencialidades en el alumno a partir de la relación que establece con el mismo, utilizando diferentes recursos o herramientas formativas o de intervención a través de actividades conjuntas. Según Porter (2010) acompaña al estudiante a que se plantee estrategias, es decir un plan, que lo ayude a transcurrir por el programa que se ha comprometido, en forma óptima, hasta lograr completar la licenciatura que le permita 
articularse a la vida laboral y profesional con mayores posibilidades de éxito. Pero para llevar a cabo esas actividades el docente tiene que desarrollar determinadas competencias, con las que no cuenta y que favorecen la acción tutoral.

Adicional a esto Vigotsky (1991:54-59) señala en su propuesta algo muy interesante y es que el aprendizaje se refiere a procesos voluntarios, acciones controladas conscientemente, mecanismos intencionales, es decir conciencia, voluntad e intención que pertenecen a la esfera de la subjetividad, dimensión humana fundamental para dicho autor. Esto permite determinar que la acción tutorial podrá tener resultados si se lleva al alumno a la reflexión, a la concientización responsable de su proceder, pues la tutoría no pretende imponer sino intercambiar y negociar áreas de oportunidad, acompañarlo en el proceso de maduración para ser responsablemente libre de tomar decisiones para proyectar su vida.

La acción tutorial es un intercambio y negociación de saberes, ideas y procesos sustentados en las vivencias del tutor que desencadenan en el sujeto tutelado, definitivamente el desarrollo del docente, la formación del mismo para ser capaz de enfrentar las situaciones con el tutorado, estará influenciado por aspectos de la personalidad del propio docente y ahí radica otra importante razón de que el docente posea las competencias requeridas para ejercer su rol de tutor y corresponder a los niveles de ayuda que requiere el estudiante tutorado.

Vigotsky procura, desde una concepción dinámica y desarrolladora del diagnóstico probar, evaluar, la capacidad de aprendizaje reservada, latente que tiene el sujeto, es decir sus potencialidades y establecer la vía para una intervención desarrolladora, que no fuese ni sobreprotectora ni estéril. En el proceso del acompañamiento de la acción tutorial, paulatinamente se debe ir de los niveles más elementales de ayuda a los más profundos y complejos.

Desde el punto de vista de las leyes y principios de la Pedagogía, la temática se enmarca en la indisoluble relación educación-sociedad, en precisamente el logro de la formación vigente, actual y oportuna del egresado del nivel superior, donde no se puede ver una aislada de la otra, pues son interdependientes para la consecución de los fines planteados. En esta relación educativa los procesos pedagógicos están abiertos y flexibles a ir más allá del contexto institucional pues se expanden a la interacción educativa social, la formación del alumno del nivel superior, bajo el acompañamiento tutorial impactará en sus ámbitos de desarrollo personal, familiar, social e institucional. La educación no se puede concebir ajena al ámbito de lo institucional y de lo social, pues como asevera Faure, p. 114 citado en Fermoso (1989), la educación es a la vez "producto y factor" de la sociedad, producto porque reproduce y refleja a la sociedad concreta en que se da y factor porque actúa como fermento renovador para una evolución interna de esa sociedad.

La concepción que se defiende contempla la indisoluble relación escuela sociedad que se tiene que manifestar en cada una de las actividades de la institución educativa, la socialización entendida como proceso por cuyo medio la persona humana aprende e interioriza, en el proceso de su vida, los elementos socioculturales de su medio ambiente, los integra a la estructura de su personalidad, bajo la influencia de experiencias y de agentes sociales significativos, y se adapta así al entorno social en cuyo seno debe vivir (Rocher, 1985:133), se convierte en una tarea importante para la formación del alumno, estas relaciones se establecen entre los alumnos, entre los alumnos profesores, entre los docentes tutores y los tutorados, así gomo agentes externos que deberás participar en dicho proceso de socialización.

A partir de las consideraciones anteriores el modelo de las competencias para la formación del docente tutor se plantea como una alternativa pedagógica capaz de enfrentar los retos de esta época y los escenarios del momento histórico actual. 
Según el Centro de Investigación en formación y Evaluación (CIFE) ha identificado cuatro grandes enfoques de las competencias a nivel mundial: funcionalista, conductual, constructivista y socioformativo, de acuerdo al tratamiento teórico de la temática que aborda este trabajo se considera este último ya que pone énfasis en la interpretación, argumentación y resolución de problemas del contexto, su base epistemológica es el pensamiento sistémico y complejo. Este enfoque define a la competencia como la actuación integral ante actividades y problemas del contexto, con idoneidad y compromiso ético, integrando el saber ser, el saber hacer y el saber conocer en una perspectiva de mejora continua (Tobón, Pimienta, García, 2010), de esta manera se fundamenta que el docente- tutor deberá desarrollar las competencias que le permitan actuar integralmente con claridad, pertinencia, ética para identificar, analizar, prever y resolver problemas de los distintos escenarios de contexto atendiendo las dimensiones personal, comunitaria-social laboral-profesional y organizacional.

En este orden de ideas, se podría aseverar que actualmente la intervención del docente no está solamente en la instrucción profesional, en el desarrollo científico, en contar con competencias pedagógicas y didácticas, requiere además aprender a proyectar una gestión eficiente y eficaz en la integración de los procesos que se desarrollan al interior de las universidades, pues ello garantizará la calidad del egresado, respondiendo a la necesidad social de formar alumnos competentes, como bien refiere Alemán, P. y colectivo de autores (2011).

Desde el punto de vista de la gestión se parte de considerar la dirección efectiva del proceso de formación del docente como primordial, entendiendo como dirección, el proceso de influencia consciente, sistemática y estable de los órganos de dirección sobre los colectivos humanos, orientando y guiando sus acciones con el fin de alcanzar determinados objetivos; basado en el conocimiento y aplicación de las leyes, principios, métodos y técnicas que regulan y son propios del sistema sobre el que influye.

La propuesta de la autora está fundamentada en la gestión formativa, considerada esta como un proceso vinculado a los problemas del contexto pedagógico y a la formación del sujeto en particular. Esta consideración desde la teoría toma como punto de partida los problemas sociales e individuales y el resultado final son los que competen y necesita el propio contexto, lo cual es expresión de su impacto y pertinencia socio-educativa que atenderá a la coherencia de las acciones formativas desde su organización, planificación, ejecución, evaluación y control y la capacidad de dar respuesta a la realidad del contexto educativo investigado desde la búsqueda de escenarios, recursos técnicos y humanos, proyectos formativos y vías estratégicas de participación e interacción colectiva y autoreflexionada en el contexto tanto interno como externo (Matos, 2009).

Esta gestión plantea como tendencia lo estratégico, a partir de ello la actuación de los diferentes actores en la institución será planeada, para lograr las metas planteadas con éxito, entre estas estrategias se considera la formación docente, la atención, orientación y acompañamiento del alumnado que permitan prevenir e intervenir desde el área de la tutoría. De igual manera desde las competencias Tobón (2010) propone algunas acciones para mejorar la práctica docente direccionar, autoevaluar, planear y actuar.

Por ello se evidencia la necesidad de que durante el ejercicio de la acción tutorial se integre no sólo lo instructivo, sino lo educativo y lo desarrollador, pues se deben formar seres humanos capaces e inteligentes, formando en ellos valores, sentimientos que identifican al individuo como ser social, además, desarrollar sus convicciones, su voluntad para contribuir a la formación de su personalidad, no se puede dejar de lado la adquisición de los conocimientos científicos, que permitirán asumir de forma consciente valores tan esenciales como la verdad, la exactitud, la creatividad, la curiosidad, 
las habilidades de razonamiento y de reflexión crítica, lo cual ayuda al estudiante a hacerse consciente de sus valores, desarrollo de capacidades, en fin permiten formar y desarrollar competencias para la vida, contribuyendo a su vez a la elaboración de su proyecto de vida responsable y es donde Porter (2012) menciona que hay tres factores claves que se deberán guiar en el estudiante, la capacidad para formular un proyecto de vida, capacidad de saber comunicar dicho proyecto y la capacidad de esperanza como consecuencia de la confianza que se desarrolle, producto de lo que el docente tutor transmita al tutorado.

De acuerdo con las propuestas de Savater (1997) quien señala. "la contraposición educación versus instrucción resulta hoy obsoleta y muy engañosa. Nadie se atreverá a sostener seriamente que la autonomía cívica y ética de un ciudadano puede fraguarse en la ignorancia de todo aquello necesario para valerse por sí mismo profesionalmente; y la mejor preparación técnica, carente del básico desarrollado de las capacidades morales o de una mínima disposición de independencia política, nunca potenciará personas hechas y derechas sino simples robots asalariados". A partir de estos planteamientos se argumenta que tanto la instrucción como la educación no se entienden por separado, están íntimamente ligadas y por ello el docente del aula, el docente que conoce el desarrollo y desempeño del estudiante debe ser también el tutor, se podría considerar la premisa de que no se puede entender la docencia sin la tutoría como una apoyo a la formación del estudiante y con mayor razón en el nivel superior, pues actualmente el mundo laboral y social en general exige personas competentes en todas las dimensiones: personal, social, técnica, comunicativa, más que solamente una instrucción especializada para insertarse en el mundo productivo, esta persona deberá contar con una serie de capacidades para la abstracción, la creatividad, la comprensión, de negociar, de un pensamiento complejo, de emprender, de ser flexible, de convivir con la diversidad, ser solidario con el otro, de ciudadanía, para ejercerse en la vida social, cultural, familiar, política y pública.

El estudio de este tema nos conduce a concretar que: el docente-tutor debe intervenir en el proceso de formación de competencias del alumnado desde la acción tutorial, mediante el acompañamiento, la orientación y la guía, para ello él debe estar consciente de los problemas que afectan a los educandos y ampliar su esfera de actuación a la familia y la comunidad, tener en cuenta la diversidad (Blanco Pérez Antonio, 2002) de los estudiantes, sus necesidades, su nuevo rol como personas activas, participantes del proceso.

Desde el punto de vista de la Didáctica, el tema objeto de investigación se fundamenta a partir del principio didáctico de la de la atención a las diferencias individuales dentro del carácter colectivo del proceso educativo, pues, las competencias que debe desarrollar el tutor deben estar orientadas a crear un clima educativo donde las personas se sientan aceptadas y apoyadas por sus propias habilidades y aportaciones, así como permitir la interacción efectiva y justa entre los miembros del grupo como motor impulsor de la zona de desarrollo próximo de cada alumno, para que a partir del desarrollo alcanzado con la ayuda del otro, - léase alumnos, docente, padres, entre otros -, se logre un desarrollo potencial, que permita desarrollar otras actividades de mayor complejidad y a la vez, manifestar formas de comunicación y socialización más profundas.

Es precisamente en la atención a la diversidad donde se manifiesta otra gama de oportunidad para la intervención preventiva de la tutoría, el comprender que cada individuo entiende su realidad de manera distinta puesto que diferentes factores lo han llevado a ser un ser humano con ciertas necesidades únicas, da la oportunidad de actuar de manera individual, personalizada, sin dejar a un lado que el estudiante a su vez forma parte de un colectivo. El reto y campo de intervención de la acción tutorial se desarrolla ante una tutoría individual y grupal, pues esto pre- 
senta la atención a la diversidad como manifiesto de la no exclusión, pues como bien comenta Artavia, A.; Cascante, L. (2007), la educación ha sido, en el transcurso de este siglo, $-y$, posiblemente lo seguirá siendo en el futuro- uno de los instrumentos más importantes con los que han contado las sociedades modernas para luchar contra las desigualdades sociales, para hacer frente a los fenómenos y a los procesos de segregación y exclusión social, para establecer, ampliar y profundizar los valores cívicos y democráticos, para impulsar el desarrollo económico y cultural, y para promover el desarrollo personal y el mejoramiento de la calidad de vida de todos sus miembros, aunque aquí cabría preguntarse, qué tan real es esta atención a los diferentes individuos que se presentan en los proceso formativos dentro de las instituciones, está el docente-tutor preparado para ello. De esta manera se puede valorar la trascendencia e implicación de contar con un docente-tutor preparado para la intervención oportuna.

Haciendo una recopilación de las propuestas de diferentes autores se determina que sería pertinente la formación docente por competencias para desenvolverse en un medio intercultural (Aguado, 2003).

Por otro lado, entre las tareas de la acción tutorial está promover la solidez de los conocimientos, habilidades, hábitos, actitudes e incluso valores.

No se puede dejar de considerar que el docente-tutor retomando los componentes de la didáctica, tendrá el encargo de regular y evaluar los progresos de los tutorados en los diferentes ámbitos de intervención, pues bien se sabe que la tutoría atenderá los diferentes espacios de desarrollo del alumno como el personal, el académico, el social, el investigativo y el laboral.

Así el docente tutor se basará en un proceso sistemático tanto individual como grupal, desarrollando estrategias planificadas de su quehacer, ello remite a una adecuada gestión de la acción tutorial mencionada anteriormente, pues su buen ejercicio requiere de una planeación previa de acuerdo a las características del contexto educativo.

Dentro de esta sistematización del proceso tutorial el docente-tutor debe establecer una buena comunicación logrando con esto un desarrollo cognitivo, personal y así llegar a una educación integral y cumplir con lo desarrollador.

La educación, la orientación y la tutoría deben preocuparse por estimular dicho desarrollo para dotar a los individuos en cada etapa de su vida de los recursos necesarios para alcanzar un nivel de madurez que les capacite para enfrentar las distintas situaciones de su vida. El protagonista ha de ser la persona con sus propias potencialidades y el contexto educativo el medio que ha de facilitar e impulsar su desarrollo.

A su vez se coincide con las autoras González, R.; González, V. (2007) y Comellas (2002) en que el nuevo rol del docente-tutor será de un orientador, guía que acompaña al estudiante en el proceso de construcción no sólo de conocimientos, sino en el desarrollo de habilidades y valores asociados a un desempeño profesional eficiente, ético y responsable, el apoyo será para el desarrollo de su autorrealización, autonomía, democracia y ciudadanía.

En este nuevo rol además se establece en un ambiente de diálogo, tolerancia, respeto, intercambio, donde se propicie el compromiso por parte de los involucrados. Un docente dinamizador de las relaciones entre la sociedad y el alumnado, el docente debe concientizarse de este compromiso, se requiere motivación intrínseca.

La propuesta además parte de la idea, con la cual la autora del presente trabajo coincide, de que educar no es una acción de unas personas (enseñantes) sobre otras (aprendices) sino un proceso de interacción, de negociación de significados, de desarrollo conjunto y compartido, orientado a la formación integral de las personas en su diversidad, otra consideración fundamental que hace es que la acción tutorial 
deberá responder a un proyecto educativo (cognición, afectos, praxis).

Por otro lado, tradicionalmente la atención personalizada del alumno ha estado en manos del área de orientación educativa y vocacional, quien durante mucho tiempo ha sido la encargada de atender al alumno en sus diferentes necesidades: escolares, afectivas, sociales, psicológicas, de salud, más ahora se sabe que entre las funciones del ser docente universitario está el ejercicio de la acción tutorial, entre otras funciones más como son la gestión, la investigación y la propia docencia y que este actor docente tutor tiene el papel protagónico en la formación competente del estudiante.

Sólo cuando se entregue a la sociedad a profesionales, seres humanos, hombres y mujeres cortados desde esta perspectiva, en verdad se estará trabajando desde el marco de la tutoría. (Santos López A, 2003).

\section{CONCLUSIONES}

» El docente tutor competente es un acompañante del estudiante en el proceso de desarrollo de su conciencia y su personalidad conformando un individuo complejo, autónomo, capaz de tomar decisiones y de trazarse metas que lo conduzcan a lograr los objetivos más profundos de desarrollo como ser humano, llegando a su autorrealización.

॥ La formación bajo el enfoque de competencias del docente tutor se plantea como una alternativa pedagógica capaz de prepararlo para enfrentar los retos de esta época y los escenarios del momento histórico en que se vive, acompañando al estudiante en el desarrollo de lo físico, lo espiritual, lo social y lo mental que han de caracterizar el proyecto de vida que debe asumir el estudiante en su tránsito por la IES y que en opinión de esta autora deben concretarse en un conjunto de acciones incluidas en una estrategia para la Facultad de Filosofía y Letras de la BUAP.

» La relación del docente tutor con sus estudiantes debe reconocerse por altos niveles de confianza y asertividad manifiestos a través de la comunicación para poder trazar acciones en el desarrollo del proyecto de vida del estudiante y que este no se vea truncado por los factores que como sabemos en la actualidad entorpecen el camino hacia un éxito profesional y social como son los desvíos de la conducta, los problemas de falta de interés por el estudio, deserción, reprobación, problemas de adicción o embarazos no deseados, etc.

»Por tanto se prescinde de una gestión formativa que vincule los problemas del contexto pedagógico y la formación del sujeto en particular y en la relación con los otros, atendiendo la coherencia de las acciones formativas desde su organización, planificación, ejecución, evaluación y control de manera estratégica.

\section{BIBLIOGRAFÍA}

Aguado, T. (2003). Pedagogía intercultural. Madrid, España: McGraw-Hill.

Alemán, P., Díaz, T., Ruíz, M. et. (2011). La gestión universitaria y el rol del profesor. La Habana. Ed. Félix Varela

Álvarez, P. (2002) La función Tutorial en la Universidad. Una apuesta por la mejora de la calidad de la enseñanza. Madrid. Ed. EOS

Artavia, C. Cascante L. (2009) Componentes teóricos para la comprensión de la pedagogía intercultural como práctica docente. Revista electrónica Educare.

Asociación Nacional de Universidades e Institutos de Educación Superior (2002). Programas Institucionales de Tutoría. Una propuesta de la 
ANUIES para su organización y funcionamiento en las instituciones de educación superior. México: ANUIES.

Benemérita Universidad Autónoma de Puebla. (2006). Fundamentos del Modelo Universitario Minerva (MUM). Puebla: BUAP

Colunga, S. (2009) Tutoría universitaria y Orientación educativa. (Conferencia Magistral dictada en el $X$ Conferencia Internacional de Ciencias de la Educación, Camagüey, Cuba, 3 de noviembre de 2009).

Comellas J. (Coord.) 2002. Las competencias del profesorado para la acción tutorial. Praxis. Monografías escuela española. Barcelona.

Cortés, R, (1977). El método dialéctico. ANUIES. Ed. Edicol, S.A

Domínguez B., Granizo S, Soler S. y Delgadillo C. Escasa. UNESCO (1998). Declaración Mundial Sobre la Educación Superior en el siglo XXI: Visión y Acción. Formación del Profesor-Tutor. Revista Educación y Futuro Digital. Enlace web: http://www.cesdonbosco.com/revista/ foro/38\%20-Belen\%2oDominguez.pdf. Recuperado en fecha 08-11-2011

Fermoso, P. (1989). Teoría de la Educación Una interpretación antropológica. CEAC, Barcelona

Galpierin, P. (1982). Antología de la Sicología pedagógica y de las edades.

Hernández, G. (1998). Cuadernos Pedagógicos: Implicaciones educativas de seis teorías psicológicas. México. CNTE-SEP.

Matos, E.a (2009). Una orientación epistémico-metodológica en la construcción del texto científico. Bolivar, Ecuador.

Matos, E.b; Cruz L. (2011). La práctica investigativa, una experiencia en la formación doctoral en ciencia pedagógica. Ediciones UO Santiago de Cuba.

Menchén, F (1999) El tutor. Dimensión histórica, social y educativa. Madrid. Editorial CCS.

Moreno, G. (1999). La enseñanza de la Resolución de Problemas matemáticos. El Blanco y el negro de algunas estrategias didácticas. http://educacion.jalisco.gob.mx/consulta/ educar/15/15Moreno.html.

Müller, M. (2011). Docentes tutores. Orientación educativa y tutorías. Ed. Bonum

OCDE (2010). Perspectivas OCDE: México, políticas clave para su desarrollo sostenible. http://www. oecd.org/mexico/45391108.pdf consultado 15 de junio 2013.

Piaget, J. (1985). Seis estudios de psicología. Barcelona, Ed. Planeta

Pimienta, J. (2007). Metodología constructivista. Guía para la planeación docente. México: Pearson.

Porter, L. Análisis conceptual de la Tutoría en la Educación Superior. Consultado el 23 de enero de 2012 en: https://docs.google.com/vie wer? $\mathrm{a}=\mathrm{v} \& \mathrm{q}=$ cache:iGaVEzZZ6gJ:www.tutoria.unam.mx/EUT2010/memoriaEUT/seminario/ANALISIS_CONCEPTUAL_PORTER. doc+Luis+PorterReyes, A.; Pérez, E.; Funchs, O. (2009). La acción tutorial en el Modelo Minerva: de la atención personalizada a los programas de acción tutorial. México. BUAP

Rocher, G. (1996) Introducción a la sociología general, Barcelona:( $1^{\mathrm{a}}$ ed., $12^{\mathrm{a}}$ imp.) Original: A General Introduction To Sociology. A Theoretical Perspective. Canadà: Macmillan, 1970

Romo, L. A. (2005) La incorporación de los programas de tutoría en las Instituciones de Educación Superior en México: ANUIES.

Romo L. A. (2011). La tutoría. Una estrategia Innovadora en el marco de los programas de atención a los estudiantes, México: ANUIES.

Romo L. A. (2011). Sistema de acompañamiento en el Nivel Medio superior. Modelo para su construcción. México: ANUIES

Santos, L. (2003). Historia e Histeria en la Tutoría: Reflexiones en educación superior. Congreso Internacional "análisis y propuestas sobre la tutoría" UAEM

Savater, F. (1997). El valor de educar. México. Ed. Instituto de estudios educativos y sindicales de América. 
Secretaria de Educación pública. Diario oficial de México, 5 de abril 2005.

Secretaria de Educación pública. Diario oficial de México, Acuerdo 623. 31 de diciembre 2011.

Tobón, S.; Pimiento, J; García, J. (2010). Aprendizaje y evaluación por competencias. Ed. Pearson. México.

Tobón, S. (2009). Formación basada en competencias: pensamiento complejo, diseño curricular y didáctica. Bogotá: Ecoe.
Vlgotsky, L. S. La conciencia como problema de la psicología del comportamiento, en Obras Escogidas (tomo 1). Madrid, Centro de publicaciones del EMC/Visor.

Vygotsky, L.S. (1991) Obras Escogidas. Tomo 1. Madrid, Aprendizaje Visor. Ministerio de Educación y Ciencias. 